\title{
Micobactérias diagnosticadas em gatos domésticos no sertão da Paraíba ${ }^{1}$
}

\author{
Millena O. Firmino ${ }^{2 *}$, Maria T.S. Frade ${ }^{2}$, Jefferson S. Ferreira ${ }^{2}$, Aline S. Alves ${ }^{2}$, \\ Cassia Y. Ikuta ${ }^{3}$, José S. Ferreira Neto ${ }^{3}$, Almir P. Souza ${ }^{4}$ e Antônio F.M. Dantas ${ }^{4}$
}

\begin{abstract}
Firmino M.O., Frade M.T.S., Ferreira J.S., Alves A.S., Ikuta C.Y., Ferreira Neto J.S., Souza A.P. \& Dantas A.F.M. 2018. [Mycobacteriae diagnosed in domestic cats in the backland of Paraiba, Brazil.] Micobactérias diagnosticadas em gatos domésticos no sertão da Paraíba. Pesquisa Veterinária Brasileira 38(7):1382-1388. Hospital Veterinário, Laboratório de Patologia Animal, Centro de Saúde e Tecnologia Rural, Universidade Federal de Campina Grande, Campus de Patos, Avenida Universitária s/n, Bairro Santa Cecília, Patos, PB 58708-110, Brazil. E-mail: millena_deoliveira@yahoo.com.br

This report describes two cases of domestic cats infected with Mycobacterium sp. in the backland of Paraiba, Northeast Brazil. The animals manifested nonspecific clinical signs, characterized by progressive weight loss, dyspnea, cough and generalized lymphadenomegaly in one cases, and clinical evolution of one and seven months respectively. Macroscopically the lesions were restricted to superficial and/or deep lymph nodes and pulmonary parenchyma, characterized by multifocal or multifocal to coalescent, yellowish and irregular nodules that presented multifocal areas with yellowish, friable and caseous as well as multifocal to coalescent, white and firm areas. Histologically, it was observed lymphadenitis and granulomatous pneumonia in both cases, varying in intensity of inflammatory response and degree of mineralization. The granulomas were constituted by macrophages and epithelioid cells, some with marked necrosis and central mineralization, surrounded by a large amount of connective tissue. In the first case there were also discrete and random granulomatous hepatitis. In both cases alcohol-acid-resistant bacilli were visualized inside the cytoplasm of macrophages in Ziehl-Neelsen staining; there was immunostaining for Mycobacterium sp. in the cytoplasm of macrophages. Through PCR was identified only the genus Mycobacterium in Case 1, and Mycobacterium bovis in Case 2. The diagnosis of Mycobacterium sp. In the cats was performed based on anatomopathological findings and immunohistochemistry. The PCR was performed the etiological diagnosis of mycobacteriosis in Case 1 and tuberculosis by $M$. bovis in Case 2. The diagnosis of diseases caused by mycobacteria in cats, especially those in which $M$. bovis was involved, is extremely important for public health highlighting the zoonotic potential of this species, since many infected animals may be asymptomatic or show nonspecific clinical signs.
\end{abstract}

INDEX TERMS: Cats, granulomatous pneumonia, lymphadenitis, Mycobacterium bovis, Paraíba, bacterioses.

\footnotetext{
${ }^{1}$ Recebido em 20 de junho de 2017.

Aceito para publicação em 6 de julho de 2017.

Parte da dissertação do primeiro autor.

${ }^{2}$ Discentes do Programa de Pós-Graduação em Medicina Veterinária, Centro de saúde e Tecnologia Rural, Universidade Federal de Campina Grande (UFCG), Campus de Patos, Av. Universitária s/n, Bairro Santa Cecília, Patos, PB 58708-110, Brasil. *Autor para correspondência: $\underline{\text { millena_deoliveira@yahoo.com.br }}$
}

\footnotetext{
${ }^{3}$ Laboratório de Zoonoses Bacterianas, Departamento de Medicina Veterinária Preventiva e Saúde Animal, Faculdade de Medicina Veterinária e Zootecnia, Universidade de São Paulo, Avenida Prof. Dr. Orlando Marques de Paiva 87, São Paulo, SP 05508-270, Brasil.

${ }^{4}$ Docentes do Programa de Pós-Graduação em Medicina Veterinária, Centro de Saúde e Tecnologia Rural, Universidade Federal de Campina Grande (UFCG), Campus de Patos, Av. Universitária s/n, Bairro Santa Cecília, Patos, PB 58708-110.
} 
RESUMO.- Descrevem-se dois casos de infecção por Mycobacterium sp. em gatos domésticos no sertão da Paraíba, Nordeste do Brasil. Os animais apresentavam emagrecimento progressivo, dispneia, tosse e linfadenomegalia generalizada em um dos casos, com evolução clínica de um e sete meses, respectivamente. Macroscopicamente as lesões estavam restritas aos linfonodos superficiais e/ou profundos e parênquima pulmonar, caracterizadas por nódulos multifocais ou multifocais a coalescentes, amarelados, irregulares que ao corte apresentavam áreas multifocais a coalescentes amareladas, friáveis e caseosa, além de áreas multifocais brancacentas e firmes. Histologicamente, verificou-se linfadenite e pneumonia granulomatosa caracterizada por áreas centrais de necrose e mineralização central circundadas por macrófagos, células epiteliais e tecido conjuntivo fibroso. No primeiro caso havia ainda hepatite granulomatosa discreta e aleatória. Em ambos os casos, foram visualizados bacilos álcool-ácido resistentes livres e no citoplasma de macrófagos na coloração de Ziehl-Neelsen. Houve imunomarcação para Mycobacterium sp. no citoplasma de macrófagos em ambos os casos. Na PCR, identificou-se apenas o gênero Mycobacterium no Caso 1 e Mycobacterium bovis no Caso 2. 0 diagnóstico de infecção por Mycobacterium sp. nos felinos foi realizado com base nos achados anatomopatológicos e imuno-histoquímica. Pela PCR foi realizado o diagnóstico etiológico de micobacteriose no Caso 1 e tuberculose por M. bovis no Caso 2. 0 diagnóstico das doenças causadas por micobactérias em felinos, principalmente aquelas em que $M$. bovis esteja envolvido, é de extrema importância para a saúde pública, destacando o potencial zoonótico desta espécie, pois muitos animais infectados podem ser assintomáticos ou apresentarem sinais clínicos inespecíficos.

TERMOS DE INDEXAÇÃO: Doença de gatos, pneumonia granulomatosa, linfadenite, Mycobacterium bovis, Paraíba, bacterioses.

\section{INTRODUÇÃO}

Doenças micobacterianas possuem caráter infectocontagioso, granulomatoso, crônico e progressivo (Quinn et al. 2005, Greene \& Gunn-Moore 2015), são causadas por bactérias da ordem Actinomycetale, família Mycobacteriaceaece e gênero Mycobacterium (Greene \& Gunn-Moore 2015). As bactérias desse gênero possuem a parede rica em lipídeos complexos e ácido micólico (Quinn et al. 2005) o que promovem a característica de álcool-ácido-resistência quando submetidos à coloração histoquímica de Ziehl-Neelsen (Malik et al. 2002, Quinn et al. 2005, Larsson et al. 2006, Greene \& Gunn-Moore 2015), embora consideradas citoquímicamente Gram-positivas, tais características da parede celular impedem a entrada dos corantes utilizados na coloração de Gram (Quinn et al. 2005, Ikuta \& Ferreira Neto 2016).

As micobactérias isoladas dos animais domésticos são divididas em dois grandes grupos. Primeiro de acordo com o tempo de crescimento da cultura, classificadas como lento ou rápido, e o outro grupo de acordo com o tipo de infecção desencadeada, seja leprosa, tuberculosa ou não tuberculosa (Greene \& Gunn-Moore 2015).

Dentre as diversas espécies com características de crescimento lento, destacam-se as bactérias do complexo
M. avium, na qual promovem a formação de granulomas na pele, no trato digestório e respiratório (Ikuta \& Ferreira Neto 2016). M. fortuitum destaca-se do grupo das bactérias de crescimento rápido por causar quadro de micobacteriose cutânea atípica, já diagnosticada no Brasil por Larsson et al. (2006) e Silva et al. (2010). Dentre as infecções lepromatosas, destaca M. lepraemurium causador da lepra felina, que não cresce em meios de cultura de rotina (Malik et al. 2002). As infecções caracterizadas como não tuberculosas são causadas por patógenos saprófitos ambientais que ocasionalmente causam doenças oportunistas ou atípicas (Hargis \& Ginn 2013) em animais de companhia, desencadeando lesões piogranulomatosas cutâneas, subcutâneas, linfáticas e a forma disseminada observadas em animais imunocomprometidos (Greene \& Gunn-Moore 2015).

M. bovis, M. tuberculosis e M. microti são bactérias que integram o complexo Mycobacterium tuberculosis, são as principais espécies de interesse na medicina veterinária por causarem a tuberculose (López 2013, Greene \& Gunn-Moore 2015), sendo as duas primeiras as espécies com maior patogenicidade (Une \& Mori 2007). Os felinos infectados por tais bactérias podem apresentar um quadro clínico de tuberculose caracterizado por perda de peso, tosse e dispneia, associado ou não a linfadenopatia (Gunn-Moore et al. 2010, Gunn-Moore et al. 2011). A forma cutânea da doença é caracterizada por nódulos multifocais com ou sem ulcerações (Gunn-Moore et al. 2010, Gunn-Moore et al. 2011) e em alguns casos, a linfadenopatia regional pode ser o único achado clínico (Gunn-Moore et al. 2011).

Em felinos os aspectos epidemiológicos da tuberculose ainda não estão definidos, pois além do consumo de leite in natura ou carne bovina contaminada (López 2013, Gibbens 2014), o hábito de caçar é considerado um fator de risco, pois algumas espécies de roedores podem albergar M. bovis e M. microti (Gunn-Moore et al. 2010, Greene \& Gunn-Moore 2015). Além disso, recentemente foi relatado dois casos de tuberculose felina por infecção nosocomial por Murray et al. (2015). Em geral, os bacilos da tuberculose não são potencialmente transmissíveis quando comparadas a outras bactérias patogênicas, visto que há necessidade de grandes inóculos ou exposição frequente e prolongada (Greene \& Gunn-Moore 2015).

Ikuta \& Ferreira Neto (2016) destacam que embora a imunossupressão possa ser apontada como um fator desencadeante, não há relatos da associação direta entre as infecções pelos Retrovírus felino e as micobacterioses. Devido à escassez de dados sobre as micobacterioses e tuberculose em felinos na literatura nacional e tendo em vista a importância da presença desses patógenos na saúde pública, bem como nos animais de companhia, objetiva-se com este estudo descrever as características clínicas, patológicas, imuno-histoquímicas e moleculares de micobactérias em felinos diagnosticados no sertão da Paraíba.

\section{MATERIAL E MÉTODOS}

Foram revisadas as fichas de necropsias de felinos domésticos e selecionados os casos sugestivos de infecção por bactérias do gênero Mycobacterium diagnosticados no Laboratório de Patologia Animal do Hospital Veterinário da Universidade Federal de Campina Grande (LPA/HV/UFCG) Campus Patos/PB, durante o período de janeiro de 
2010 a dezembro de 2015. Avaliaram-se os dados epidemiológicos (raça, sexo, idade e procedência do animal) os sinais clínicos, lesões macroscópicas e histológicas descritas nos protocolos de necropsias. Para mais detalhamento dos dados epidemiológicos e dos sinais clínicos foram revisadas as fichas clínicas de atendimento referentes a esses animais nos arquivos da Clínica Médica de Pequenos Animais (CMPA).

Os fragmentos provenientes de necropsias haviam sido fixados em formol a $10 \%$ e processados rotineiramente para histopatologia. As secções histológicas coradas pela hematoxilina e eosina (HE) foram avaliadas visando caracterizar a resposta inflamatória de cada caso. Posteriormente, foi realizada a técnica histoquímica especial de Ziehl-Neelsen para visualização do agente.

Blocos de parafina contendo fragmentos de pulmão e linfonodo traqueobrônquico (Caso 1) e linfonodo poplíteo (Caso 2) foram selecionados e processados para imuno-histoquímica com anticorpo anti-Mycobacterium sp. Foram realizados cortes de $3 \mu \mathrm{m}$ de espessura das amostras de tecido e aplicados sob lâminas positivadas (ImmunoSlide-EasyPath ${ }^{\circledR}$ ). Após a desparafinização e desidratação das lâminas, foi realizado o bloqueio da peroxidase endógena com peróxido de hidrogênio a 3\% (2x de 10 minutos). A recuperação antigênica foi realizada com solução tampão de Citrato $(\mathrm{pH} \mathrm{6,0)}$ em forno microondas por 10 minutos em potência máxima. 0 bloqueio das reações inespecíficas foi realizado com caseína (leite em pó desnatado) a 5\% por 60 minutos em temperatura ambiente. Os cortes foram incubados em câmara úmida $37^{\circ} \mathrm{C}$ por 60 minutos com o anticorpo primário policlonal anti-Mycobacterium sp. na diluição de 1:1000 em diluente de anticorpo (PBS-pH 7.4, EasyPath). Utilizou o sistema de detecção por polímero HRP, incubado a temperatura ambiente por $10 \mathrm{~min}$ em câmara úmida e marcados através da adição do cromógeno 3,3' diaminobenzidine (DAB; Dako) por 2 minutos. A contra-coloração foi com hematoxilina de Harris. Como controle negativo, utilizou-se a mesma secção do tecido analisado na porção inferior da lâmina, com substituição do anticorpo primário por diluente de anticorpo (PBST). Como controle positivo foi utilizado fragmento de intestino de um caso de paratuberculose.

Cortes dos blocos de parafina contendo fragmentos de pulmão e linfonodo traqueobrônquico (Caso 1) e linfonodo poplíteo (Caso 2), foram inseridos em microtubos de $2 \mathrm{~mL}$ e enviados para o Laboratório de Zoonoses Bacterianas (LZB) do Departamento de Medicina Veterinária Preventiva e Saúde Animal (VPS) da Faculdade de Medicina Veterinária e Zootecnia (FMVZ) da Universidade de São Paulo (USP). Anteriormente à extração de DNA, a parafina foi removida através da adição de $1 \mathrm{~mL}$ de xilol, com homogeneização por vórtex e centrifugação a 12.800 r.p.m. por 5 minutos. 0 sobrenadante foi removido cuidadosamente para não tocar o pelete. Em seguida, adicionou-se $1 \mathrm{~mL}$ de etanol $100 \%$, com os mesmos procedimentos de homogeneização, centrifugação e remoção do sobrenadante. Esse processo foi repetido de cinco a dez vezes, até a eliminação de toda parafina. A extração de DNA foi realizada com o auxílio de QIAamp ${ }^{\circledR}$ DNA Mini Kit (Qiagen, Hilden, Alemanha), segundo as instruções do fabricante. A identificação do agente foi realizada através de uma série de protocolos de PCR, descritos por Hermans et al. (1990), Cousins et al. (1991), Telenti et al. (1993), Warren et al. (2006).

\section{RESULTADOS}

Durante o período estudado foram realizadas 407 necropsias de felinos. Destes, dois felinos foram diagnosticados com infecção por Mycobacterium sp., representando 0,49\% da causa morte e/ou eutanásia. Os dois felinos eram provenientes da zona urbana do município de Patos, localizado na mesorregião do sertão da Paraíba, de clima semiárido, Nordeste do Brasil. 0 primeiro caso ocorreu em fevereiro de 2010 e o segundo em março de 2015. A epidemiologia, sinais clínicos, evolução, órgãos afetados e diagnósticos morfológicos encontram-se descritos no Quadro 1.

No Caso 1, o animal apresentava escore corporal ruim, os pulmões não colapsados com áreas nodulares multifocais a coalescentes amareladas, discretamente elevadas na superfície pleural, medindo aproximadamente $2,0 \mathrm{~cm}$ de diâmetro, firmes, que ao corte se aprofundavam ao parênquima. Os linfonodos traqueobrônquicos estavam aumentados de volume e apresentavam lesões semelhantes, com áreas caseosas discretas e áreas multifocais brancacentas firmes.

No Caso 2, o animal apresentava escore corporal regular e aumento de volume bilateral dos linfonodos superficiais (Fig.1A) (linfonodos submandibular, retrofaríngeo, pré-escapular e poplíteo) e profundos (cervical profundo, mediastínicos, hepatogástrico, pancreático e mesentéricos). Esses linfonodos apresentavam superfície irregular com múltiplos nódulos amarelados. 0 linfonodo submandibular esquerdo media $4,5 \times 3,0 \times 1,0 \mathrm{~cm}$ e o direito $2,0 \times 1,5 \times 1,0 \mathrm{~cm}$; o linfonodo pré-escapular esquerdo media $1,5 \times 1,5 \times 0,8 \mathrm{~cm}$ e o direito 1,0x1,0x0,5cm; o linfonodo poplíteo direito media $1,0 \times 1,0 \times 0,5 \mathrm{~cm}$; o linfonodo mesentérico media $3,5 \times 2,0 \times 1,5 \mathrm{~cm}$; o linfonodo pancreático media $1,6 \times 1,0 \times 0,8 \mathrm{~cm}$ de tamanho. Ao corte, todos os linfonodos apresentavam áreas multifocais a coalescentes amareladas, friáveis e caseosas (Fig.1B),

\section{Quadro 1. Características epidemiológicas, clínicas, evolução, órgãos afetados e diagnóstico morfológico das infecções micobacterianas diagnosticados em felinos no Laboratório de Patologia Animal da Universidade Federal de Campina Grande, Patos/PB}

\begin{tabular}{|c|c|c|c|c|c|}
\hline Caso & $\begin{array}{l}\text { Raça } \\
\text { Sexo } \\
\text { Idade }\end{array}$ & Sinais clínicos & Evolução & $\begin{array}{l}\text { Órgãos } \\
\text { afetados }\end{array}$ & $\begin{array}{l}\text { Diagnóstico } \\
\text { morfológico }\end{array}$ \\
\hline 1 & $\begin{array}{l}\text { SRD }{ }^{\text {a }} \text { Fêmea } \\
24 \text { meses }\end{array}$ & $\begin{array}{l}\text { Apatia, anorexia, dispneia, } \\
\text { tosse, emagrecimento }\end{array}$ & 1 mês & $\begin{array}{l}\text { Pulmão, } \\
\text { linfonodo } \\
\text { traqueobrônquico, fígado }\end{array}$ & $\begin{array}{l}\text { Pneumonia, linfadenite, } \\
\text { hepatite granulomatosa }\end{array}$ \\
\hline 2 & $\begin{array}{l}\text { SRD }{ }^{\mathrm{a}} \text { Macho } \\
13 \text { meses }\end{array}$ & $\begin{array}{l}\text { Anorexia, dispneia, } \\
\text { tosse, emagrecimento, } \\
\text { linfadenomegalia }\end{array}$ & 7 meses & $\begin{array}{l}\text { Pulmão, } \\
\text { linfonodos superficiais, } \\
\text { mediastínicos e } \\
\text { mesentéricos }\end{array}$ & $\begin{array}{l}\text { Pneumonia, linfadenite } \\
\text { granulomatosa }\end{array}$ \\
\hline
\end{tabular}

a Sem raça definida. 
além de áreas multifocais brancacentas e firmes (Fig.1C), principalmente na cortical, causando perda da distinção entre as regiões cortical e medular. Nos pulmões havia áreas multifocais amareladas discretamente elevadas na superfície pleural, variando de 0,1 a $0,2 \mathrm{~cm}$ de diâmetro, principalmente no lobo caudal direito (Fig.1D).

Histologicamente verificou-se nos dois casos, linfadenite e pneumonia granulomatosa (Fig.2A-C), variando de intensidade de resposta inflamatória e o grau de mineralização. No pulmão do caso 1 , verificou-se granulomas multifocais a coalescentes, constituídos centralmente por necrose, macrófagos e células epitelioides e mais perifericamente havia discreto infiltrado inflamatório de neutrófilos, circundados por acentuada proliferação de tecido conjuntivo fibroso. Nas áreas adjacentes aos granulomas havia acentuado infiltrado de macrófagos com citoplasma espumoso na luz alveolar. No linfonodo traqueobrônquico, havia áreas semelhantes multifocais de granulomas discretos distribuídos nas regiões cortical e medular, além de granulomas maiores com acentuada necrose e mineralização central, circundados por grande quantidade de tecido conjuntivo fibroso. No fígado observou-se discretos granulomas distribuídos de forma aleatória (Fig.2D).

No Caso 2, em todos os linfonodos afetados verificavam-se áreas multifocais a coalescentes de granulomas com intensidade variável de necrose, mineralização e fibrose. Em algumas áreas, havia discreto infiltrado inflamatório mononuclear, constituído por plasmócitos, linfócitos e raros macrófagos em meio ao tecido conjuntivo fibroso. No parênquima nodal havia discreto número de células Mott. No parênquima pulmonar os granulomas eram semelhantes e discretos.

Em ambos os casos na coloração de Ziehl-Neelsen, foram observados nos linfonodos e pulmões poucos bacilos álcool-ácido-resistentes (BAAR) (Fig.3), no citoplasma de macrófagos e livres entre as células inflamatórias e nas áreas de necrose dos granulomas, característicos de Mycobacterium sp.

Nos dois casos, observou-se forte imunomarcação para Mycobacterium sp. no citoplasma de macrófagos. Na PCR, identificou-se apenas o gênero Mycobacterium no Caso 1 e Mycobacterium bovis no Caso 2.
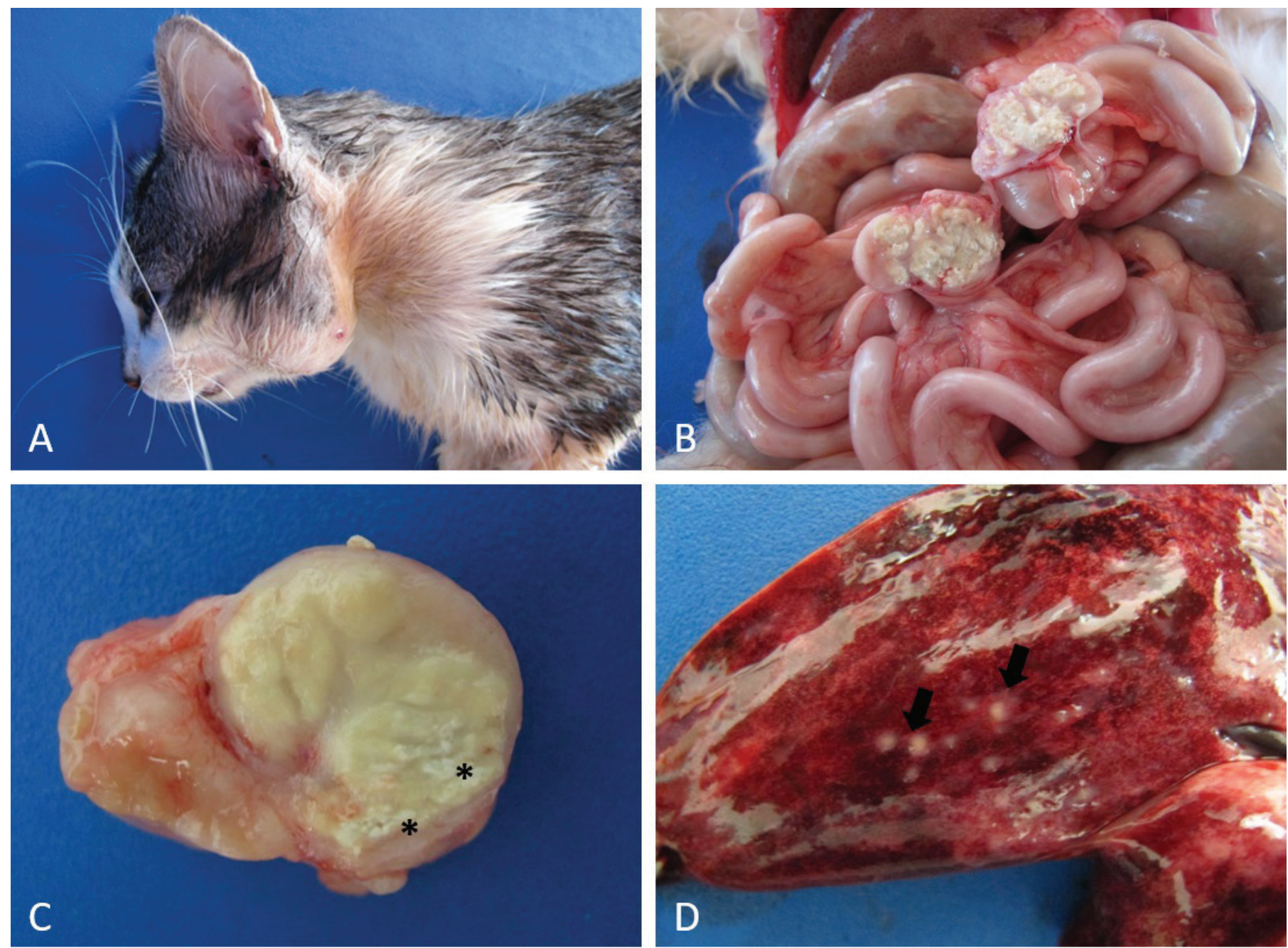

Fig.1. Infecção micobacteriana em gatos domésticos. (A) Observa-se linfonodo submandibular esquerdo aumentado de volume. (B) Linfonodo mesentérico. Observam-se áreas amareladas irregulares friáveis e caseosa na superfície de corte. (C) Linfonodo poplíteo.Visualizam-se áreas amarelas friáveis e caseosa associada a áreas multifocais brancacentas e firmes (asterisco). (D) Pulmão. Observam-se no lobo pulmonar caudal direito áreas multifocais amareladas discretamente elevadas na superfície pleural (setas). 

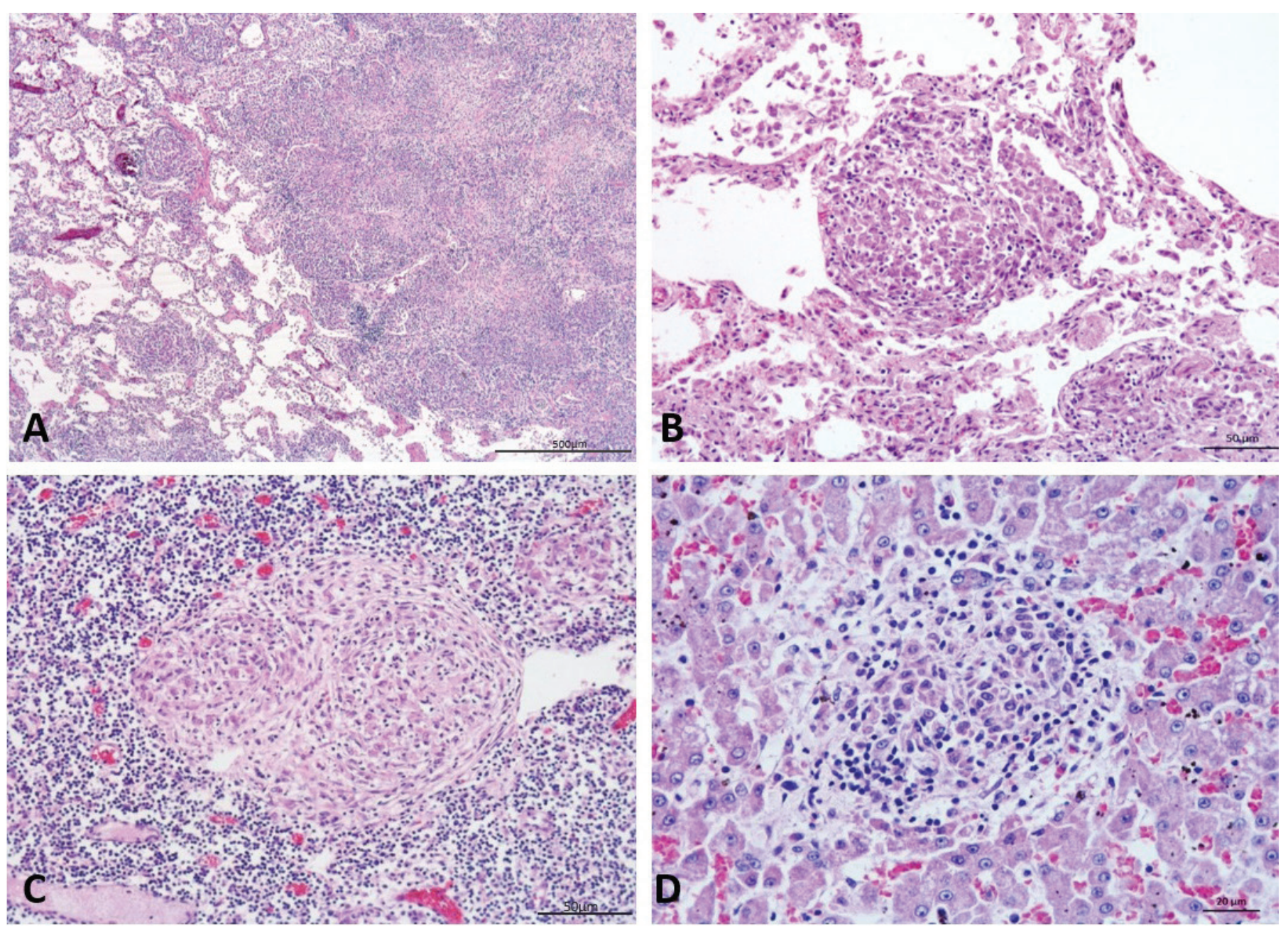

Fig.2. Infecção micobacteriana em gatos domésticos. (A) Pulmão. Observam-se áreas multifocais a coalescentes de granulomas. HE, barra $=500 \mu \mathrm{m}$. (B) Pulmão. Observa-se granuloma focal. HE, barra=50 $\mu \mathrm{m}$. (C) Linfonodo traqueobrônquico. Observam-se granulomas multifocais a coalescentes. HE, barra $=50 \mu \mathrm{m}$. (D) Fígado. Observam-se granuloma focal. HE, barra=20 $\mu \mathrm{m}$.

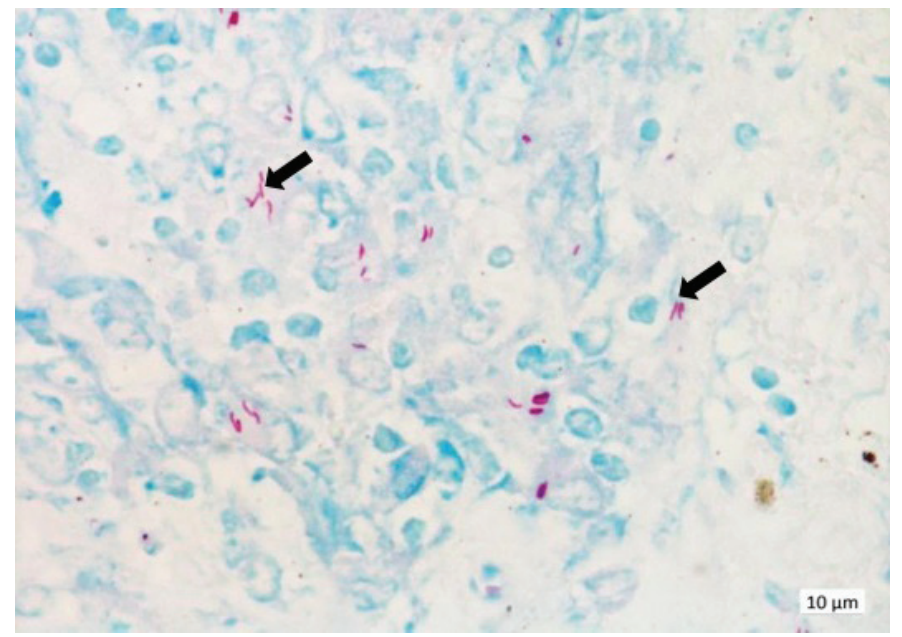

Fig.3. Infecção micobacteriana em gatos domésticos. Linfonodo traqueobrônquico. Observam-se bacilos álcool-ácido-resistentes (setas) livre e no citoplasma de macrófagos. Ziehl-Neelsen, barra $=10 \mu \mathrm{m}$.

\section{DISCUSSÃO}

O diagnóstico de infecção por Mycobacterium sp. nos felinos foi realizado com base nos achados anatomopatológicos e associados à imuno-histoquímica. Pela PCR foi realizado o diagnóstico etiológico de micobacteriose no Caso 1 e tuberculose por M. bovis no Caso 2. Acredita-se que no Caso 1 a não determinação da espécie ocorreu possivelmente pelo tempo que o material permaneceu em parafina e formol até a realização da técnica, podendo ter ocorrido à degradação do material genético da bactéria.

Pela distribuição das lesões, acredita-se que no Caso 1, a infecção ocorreu por via aerógena. Dentre as infecções causadas pelo gênero Mycobacterium que apresentam afinidade pelo tecido pulmonar, destaca-se $M$. tuberculosis que geralmente ocasiona pneumonia granulomatosa, pois esta espécie necessita de tecidos com grande quantidade de oxigênio (Greene \& Gunn-Moore 2015). Além disso, micobactérias não tuberculosas de crescimento rápido, como as bactérias do complexo M. chelonae-abscessus e M. fortuitum desencadeiam quadro de pneumonia piogranulomatosa em cães e gatos (Ikuta \& Ferreira Neto 2016). 
No Caso 2, pela distribuição das lesões, a via mais provável de infecção foi a via oral, uma vez que, quando se trata de infecção por M. bovis, o trato gastrointestinal (TGI) se torna a porta de entrada mais comum em cães e gatos (Greene \& Gunn-Moore 2015), pois a infecção ocorre principalmente através do consumo de carne e leite de bovinos infectados, sem que houvesse processo de pasteurização ou qualquer tipo de tratamento térmico prévio (López 2013). Além disso, o fornecimento de carne e vísceras cruas de bovinos infectados ou ainda a ingestão de roedores silvestres que albergam o M. bovis (Greene \& Gunn-Moore 2015). A alta prevalência da tuberculose bovina (Ramos 2016) e a presença de M. bovis no leite de vacas infectadas (Ramos et al. 2016) no sertão da Paraíba, associadas a prática comum de administração de leite cru aos gatos jovens nessa região, pode ser considerado um fator de risco para a infecção nessa espécie animal.

A epidemiologia da doença ainda não é bem definida, mas acredita-se que os cães e gatos em contato direto com o homem, bovinos ou roedores infectados, sirvam de animais sentinelas para a doença principalmente em locais com alta prevalência da infecção por $M$. bovis em zonas rurais e nas áreas suburbanas (Gibbens 2014, Greene \& Gunn-Moore 2015). Nestes casos, os cães e gatos são considerados como potenciais disseminadores da doença quando o agente se encontra no TGI e no sistema respiratório, excretando os microrganismos pelas fezes ou por secreções respiratórias, dependendo da localização da lesão ou forma clínica da doença e raramente são responsáveis pela transmissão da bactéria para humanos (Greene \& Gunn-Moore 2015).

0 segundo caso pode ser classificado como uma forma disseminada da tuberculose, pois se verificou linfadenite granulomatosa generalizada com discreto envolvimento pulmonar. Além disso, gatos com infecção generalizada por Mycobacterium bovis podem desenvolver lesões oculares (Formston 1994, Ikuta \& Ferreira Neto 2016) e também há relato de um leão com lesões ósseas e articulares (Kirberger et al. 2006). Greene e Gunn-Moore (2015) destacam que os animais imunossuprimidos tendem a desencadear infecção local ou disseminada, devido à deficiência na imunidade celular, pois os bacilos viáveis ficam no interior de células fagocitárias, multiplicando-se em consequência da ineficiência do hospedeiro em controlar a infecção.

Clinicamente, a tuberculose em cães e gatos é frequentemente considerada como subclínica (Greene \& Gunn-Moore 2015), tanto em fazendas com histórico de tuberculose por $M$. bovis (Mota et al. 2001, Wilkins et al. 2008), quanto em ambientes com pessoas infectadas por M. tuberculosis ou M. bovis (Ikuta \& Ferreira Neto 2016). No entanto, os animais deste estudo apresentaram os sinais clínicos inespecíficos e variaram de acordo com a localização das lesões, semelhante ao descrito por Greene e Gunn-Moore (2015). O comprometimento pulmonar nas infecções micobacterianas pode desenvolver episódios de febre, perda de peso, anorexia, dispneia e tosse não produtiva (Gunn-Moore et al. 2010, Gunn-Moore et al. 2011, Ikuta \& Ferreira Neto 2016), como observado nos animais estudados. A lesão pulmonar do Caso 2 era discreta, portanto a dispneia e a tosse neste animal podem estar relacionadas com o aumento dos linfonodos submandibulares, retrofaríngeos e mediastínicos, o que provavelmente dificultava a passagem do ar.
O diagnóstico diferencial nesses casos que cursam com linfadenite e pneumonia granulomatosa deve ser incluído principalmente as infecções por Actinomyces spp., Nocardia spp., Cryptococcus neoformans e Aspergillus spp. (Ikuta \& Ferreira Neto 2016). Além dessas infecções bacterianas e fúngicas, devem ser também incluídas as neoplasias (López 2013, Ikuta \& Ferreira Neto 2016) que cursam com dispneia e emagrecimento progressivo, associados à linfadenomegalia generalizada e lesões nodulares de aparência sólida e não caseosa nos pulmões (López 2013).

\section{CONCLUSÕES}

O diagnóstico das doenças causadas por micobactérias em felinos, principalmente aquelas em que Mycobacterium bovis esteja envolvido, já que estes animais podem servir como reservatório do agente, pode promover a manutenção do microrganismo no ambiente e ocasionar a disseminação para o rebanho bovino da região ou a infecção para os humanos.

Diante da dificuldade de crescimento e isolamento destes microrganismos em meios convencionais da rotina dos laboratórios de microbiologia, a histopatologia auxilia no diagnóstico, mas a imuno-histoquímica e os testes moleculares se tornam altamente relevantes para o diagnóstico etiológico.

\section{REFERÊNCIAS}

Cousins D.V., Wilton S.D. \& Francis B.R. 1991. Use of DNA amplification for the rapid identification of Mycobacterium bovis. Vet. Microbiol. 27(2):187-195. <http://dx.doi.org/10.1016/0378-1135(91)90010-D><PMid:2063549>

Formston C. 1994. Retinal detachment and bovine tuberculosis in cats. J. Small Anim. Pract. 35(1):5-8. <http://dx.doi.org/10.1111/j.1748-5827.1994. tb03572.x>

Gibbens N. 2014. Mycobacterium bovis infection in cats. Vet. Rec. 174(13):331332. <http://dx.doi.org/10.1136/vr.g2344><PMid:24676264>

Greene C.E. \& Gunn-Moore D.A. 2015. Infecções micobacterianas, p.522-549. In: Greene C.E. (Ed.), Doenças Infecciosas em Cães e Gatos. $4^{a}$ ed. Guanabara Koogan, Rio de Janeiro. 1387p.

Gunn-Moore D.A., Dean R. \& Shaw S. 2010. Mycobacterial infections in cats and dogs. In Practice 32(9):444-452. <http://dx.doi.org/10.1136/inp.c5313>

Gunn-Moore D.A., McFarland S., Brewer J., Crawshaw T., Clifton-Hadley R.S., Kovalik M. \& Shaw D.J. 2011. Mycobacterial disease in cats in Great Britain 1: bacterial species, geographical distribution and clinical presentation of 339 cases. J. Feline Med. Surg. 13(12):934-944. <http://dx.doi.org/10.1016/j. jfms.2011.07.012><PMid:22079343>

Hargis A.M. \& Ginn P.E. 2013. 0 tegumento, p.977-1987. In: McGavin M.D. \& Zachary J.F. (Eds), Bases da Patologia em Veterinária. 5aㅡ ed. Elsevier, Rio de Janeiro. 1324p.

Hermans P.W.M., Van Soolingen D., Dale J.W., Schuitema A.R.J., McAdam R.A., Catty D. \& Van Embden J.D.A. 1990. Insertion element IS986 from Mycobacterium tuberculosis: a useful tool for diagnosis and epidemiology of tuberculosis. J. Clin. Microbiol. 28(9):2051-2058. <PMid:1977765>

Ikuta C.Y. \& Ferreira Neto J.S. 2016. Micobacterioses e tuberculose em cães e gatos, p.413-422. In: Megid J., Ribeiro M.G. \& Paes A.C. (Eds), Doenças Infecciosas em Animais de Produção e de Companhia. Roca, Rio de Janeiro. $1272 \mathrm{p}$.

Kirberger R.M., Keet D.F. \& Wagner W.M. 2006. Radiologic abnormalities of the appendicular skeleton of the lion (Panthera leo): incidental findings and Mycobacterium bovis-induced changes. Vet. Radiol. Ultrasound 47(2):145-152. <http://dx.doi.org/10.1111/j.1740-8261.2006.00121.x> $<$ PMid:16553146> 
Larsson C.E., Delayte E.H., Balda N.S., Michalany N.S., Pinheiro S.R., Otsuka M. \& Roxo E. 2006. Dermatite micobacteriana atípica em gato: relato de caso. Arq. Bras. Med. Vet. Zootec. 56(6):1092-1098. <http://dx.doi.org/10.1590/ S0102-09352006000600018>

López A. 2013. Sistema respiratório, mediastino e pleuras, p.461-541. In: McGavin M.D. \& Zachary J.F. (Eds), Bases da Patologia em Veterinária. $5^{a}$ ed. Elsevier, Rio de Janeiro. 1324p.

Malik R., Hughes M.S., James G., Martin P., Wigney D.I., Canfield P.J., Chen S.C.A., Mitchell D.H. \& Love D.N. 2002. Feline leprosy: two different clinical syndromes. J. Fel. Med. Surg. 4(1):43-59. <http://dx.doi.org/10.1053/ jfms.2001.0151><PMid:11869054>

Mota P.M.P.C., Lobato F.C.F., Assis R.A., Lage A.P. \& Parreiras P.M. 2001. Isolamento de Mycobacterium bovis em cão. Arq. Bras. Med. Vet. Zootec. 53(4):1-3. <http://dx.doi.org/10.1590/S0102-09352001000400003>

Murray A., Dineen A., Kelly P., McGoey K., Madigan G., NiGhallchoir E. \& Gunn-Moore D.A. 2015. Nosocomial spread of Mycobacterium bovis in domestic cats. J. Feline Med. Surg. 17(2):173-180. <http://dx.doi. org/10.1177/1098612X14529768><PMid:24710594>

Quinn P.J., Markey B.K., Carter M.E., Donnelly W.J. \& Leonard F.C. 2005. Gênero Mycobacterium, p.106-114. In: Ibid (Eds), Microbiologia Veterinária e Doenças Infecciosas. Artmed, Porto Alegre. 512p.

Ramos J.M. 2016. Isolamento e identificação de Mycobacterium spp. em bovinos positivos no teste de tuberculinização. Dissertação de Mestrado, Universidade Federal de Campina Grande, Patos, PB.
Ramos J.M., Heinemann M.B., Ferreira-Neto J.S., Souza-Filho A.F., Cárdenas N.C., Alves C.J. \& Azevedo S.S. 2016. Isolation and identification of Mycobacterium bovis in milk from cows in northeastern Brazil. Ciência Rural 46(12):21662169. <http://dx.doi.org/10.1590/0103-8478cr20160416>

Silva D.A., Gremião I.D.F., Menezes R.C., Pereira S.A., Figueiredo F.B., Ferreira R.M.C. \& Pacheco T.M.V. 2010. Micobacteriose cutânea atípica felina autóctone no município do Rio de Janeiro, Brasil. Acta Scient. Vet. 38(3):327-331.

Telenti A., Marchesi F., Balz M., Bally F., Böttger E.C. \& Bodmer T. 1993. Rapid identification of mycobacteria to the species level by polymerase chain reaction and restriction enzyme analysis. J. Clin. Microbiol. 31(2):175-178. <PMid:8381805>

Une Y. \& Mori T. 2007. Tuberculosis as a zoonosis from a veterinary perspective. Comp. Immunol. Microbiol. Infect. Dis. 30(5/6):415-425. <http://dx.doi. org/10.1016/j.cimid.2007.05.002><PMid:17706284>

Warren R.M., Gey Van Pittius N.C., Barnard M., Hesseling A., Engelke E., De Kock M., Gutierrez M.C., Chege G.K., Victor T.C., Hoal E.G. \& Van Helden P.D. 2006. Differentiation of Mycobacterium tuberculosis complex by PCR amplification of genomic regions of difference. Int. J. Tuberc. Lung Dis. 10(7):818-822. <PMid:16850559>

Wilkins M.J., Bartlett P.C., Berry D.E., Perry R.L., Fitzgerald S.D., Bernardo T.M., Thoen C.O. \& Kaneene J.B. 2008. Absence of Mycobacterium bovis infection in dogs and cats residing on infected cattle farms: Michigan, 2002. Epidemiol. Infect. 136(12):1617-1623.<http://dx.doi.org/10.1017/ S0950268808000447><PMid:18325127> 